\title{
Ex-Vivo anti-inflammatory and antimicrobial activities of the leaves of Bauhinia acuminata
}

\author{
Md. Reyad-Ul-Ferdous 1, 2, *, Sayma Akhter², Md. Zahirul Islam Khan², Md. Eshak Khan², \\ Md. Atiqul Islam², Md. Sharif Ullah' \\ ${ }^{1}$ Department of Pharmacy, Progati Medical Institute, Dhaka-1207, Bangladesh \\ ${ }^{2}$ Department of Pharmacy, State University of Bangladesh, Dhaka-1205, Bangladesh
}

\section{Email address:}

rockyreyad@yahoo.com (Md. Reyad-Ul-Ferdous), saymalaboni@gmail.com (S. Akhther), zahirkhan036@gmail.com (Md. Z. I. Khan), sawpon.rana@gmail.com (Md. E. Khan), msharifullah1990@gmail.com (Md. S. Ullah), a14mdais@student.his.se (Md. A. Islam)

\section{To cite this article:}

Md. Reyad-Ul-Ferdous, Sayma Akhter, Md. Zahirul Islam Khan, Md. Eshak Khan, Md. Atiqul Islam, Md. Sharif Ullah. Ex-Vivo Anti-Inflammatory and Antimicrobial Activities of the Leaves of Bauhinia acuminata. American Journal of Life Sciences.

Vol. 2, No. 5, 2014, pp. 267-270. doi: 10.11648/j.ajls.20140205.13

\begin{abstract}
In present study, the methanol extracts and all fractions of leaves of Bauhinia acuminata were subjected to various biological screening such as membrane stabilizing activity and antimicrobial screening. This investigation suggested that, leaves of Bauhinia acuminata were highly effective in the membrane stabilizing activity as the extractives prevented the lysis of erythrocyte by hypotonic solution and heat induced. In hypotonic solution induced condition the highest membrane stabilizing activity was exhibited by the Pet ether soluble fraction (PESF-418.26\%) followed by carbon tetra chlororide soluble fraction (CTCSF-418.26\%). Significant amount of membrane stabilizing activity were also present in methanol soluble fraction (MESF-13.46\%) and aqueous soluble fraction (AQSF-167.30\%). On the other hand, heat induced condition the maximum membrane stabilizing activity was exhibited by the carbon tetra chlororide soluble fraction (CTCSF-853.3\%) followed by Methanol soluble fraction (MESF-423.88\%). Significant amount of membrane stabilizing activity were also present in Pet ether soluble fraction (PESF-81.77\%) and aqueous soluble fraction (AQSF-40.46\%). In this study, the antimicrobial activity, among all extractives of leaves of Bauhinia acuminate was found to be negligible.
\end{abstract}

Keywords: Bauhinia Acuminate, Anti-Inflammatory, Antimicrobial Activity

\section{Introduction}

Bauhinia acuminata belonging to the family; Fabaceae, an evergreen large shrub, grows in disturbed areas of Southeast Asia such as Indonesia, Malaysia or the Philippines [1]. In Bangladesh, it grows in hilly forests of Sylhet and Chittagong. It grows 2 to 3 meters tall. Leaves with petioles $1.5-4 \mathrm{~cm}$ long; broadly ovate or sub orbicular, blades ovate, divided about $1 / 3$ their length, membranous, densely puberulent abaxially, glabrous adaxially, apex of lobes acute, base cordate to rounded. They are apical cleft up to $5 \mathrm{~cm}$ deep with the 6 to 15 centimeters long and broad. The flowers are 8 to 12 centimeters in diameter with fragrant, with five white petals, ten yellow-tipped stamens and a green stigma [2]. The species occurs in deciduous forests and scrub. Several chemical compounds including palmitic acid, three phthalic acid esters, phthalic acid, gallic acid, ursolic acid were identified from the leaves of B. acuminata [3]. In this study, we report the anti-inflammatory activity and the antimicrobial activity of the methanol leaf extract of this plant.

As a part of our continuous search on medicinal plants of Bangladesh, the organic soluble materials of leaves of Bauhinia acuminata were evaluated for anti-inflammatory and antimicrobial activities.

\section{Materials and Methods}

\subsection{Plant Material}

The leaves of $B$. acuminate were collected from Mirpur Botanical Garden, Dhaka, Bangladesh, in the month of November 2011. A voucher specimen for this plant has been maintained in Bangladesh National Herbarium, Dhaka, Bangladesh (Accession no. 38305). The fruit were picked and washed with water to remove all unwanted plant materials and sand, air dried under light exposure $\left(27^{\circ} \mathrm{C}-30^{\circ} \mathrm{C}\right.$ for 7 days $)$, 
pulverized in a mill and stored in an airtight container for further study.

\subsection{Preparation of Extract}

The air dried and powdered fruit (500 gm) of B. acuminate was macerated in $2.5 \mathrm{~L}$ of methanol for 7 days and then filtered through a cotton plug followed by Whatman filter paper number 1 . All the extracts were concentrated with a rotary evaporator at low temperature $\left(40-45^{\circ} \mathrm{C}\right)$ with reduced pressure. The concentrated methanolic extract (ME) was fractionated by modified Kupchan partitioning method [4] and the resultant partitionates i.e., pet-ether (PESF), carbon tetrachloride (CTCSF), chloroform (CSF), and aqueous (AQSF) soluble fractions were used for the experimental processes.

\subsection{Drugs and Chemicals}

The drugs such as Ciprofloxacillin and nutrient agar medium (Difco) were collected from Opsonin Pharmaceuticals Ltd, Dhaka, Bangladesh as gift sample. Chemicals were obtained from Merck limited.

\subsection{Membrane Stabilizing Activity}

The membrane stabilizing activity of the extractives was assessed by using hypotonic solution-induced and heat-induced hemolysis of mice erythrocyte by the method developed by [5, 6] as well as describe by [7]. In hypotonic solution-induced method, the test sample consisted of stock erythrocyte $(\mathrm{RBC})$ suspension $(0.50 \mathrm{~mL})$ is mixed with $5 \mathrm{~mL}$ of hypotonic solution $(50 \mathrm{mM} \mathrm{NaCl})$ in $10 \mathrm{mM}$ sodium phosphate buffered saline ( $\mathrm{pH}$ 7.4) containing either the extracts $(1.0 \mathrm{mg} / \mathrm{mL})$ or acetyl salicylic acid $(0.1 \mathrm{~g} / \mathrm{mL}) .0 .5$ $\mathrm{mL}$ of RBCs mixed with hypotonic-buffered saline alone for prepared control sample. The mixture sample was incubated for $10 \mathrm{~min}$ at room temperature and centrifuged for $10 \mathrm{~min}$ at $3000 \mathrm{~g}$ as well as taken the absorbance of the supernatant at $540 \mathrm{~nm}$. The percentage inhibition of either membrane stabilization or haemolysis was determined using the following equation $-\%$ inhibition of haemolysis $=100 \mathrm{x}$ (OD1-OD2/OD1)

Where, OD1=optical density of hypotonic - buffered saline solution alone (control) and OD2= optical density of test sample in hypotonic solution.

In heat-induced haemolysis, isotonic buffer containing aliquots $(5 \mathrm{ml})$ of the different extracts were put into two duplicate sets of centrifuge tubes. Two tubes were prepared with same amount of vehicle and another tube as control. Erythrocyte suspension $(30 \mu \mathrm{L})$ was added to each tube and mixed gently by inversion. One pair was maintained at (0-5) o $\mathrm{C}$ in an ice bath while the other pair of the tubes was incubated at $54 \mathrm{o} \mathrm{C}$ for $20 \mathrm{~min}$ in a water bath. The vehicle and Erythrocyte suspension containing mixture was centrifuged for $3 \mathrm{~min}$ at $1300 \mathrm{~g}$ and the absorbance of the supernatant was determinated at $540 \mathrm{~nm}$. The acceleration of hemolysis or percentage inhibition tests was calculated according to the equation:
$\%$ Inhibition of hemolysis $=100 \times$ [1-(OD2-OD1/OD3-OD1)

Where, OD1 = optical density of unheated test sample, $\mathrm{OD} 2=$ optical density of heated test sample and OD3=optical density of heated control sample.

\subsection{Antimicrobial Activity}

The antimicrobial test was performed by the disc diffusion method [8] against eleven bacteria and three fungi (Table-1) collected as pure cultures from the Institute of Nutrition and Food Science (INFS), University of Dhaka, Bangladesh. The fungal and bacterial suspensions were used to inoculate Petri plates $(90 \mathrm{~mm})$ and wells $(6 \mathrm{~mm})$ were filled with the extracts $(400 \mu \mathrm{g} / \mathrm{disc})$. Standard disc of Ciprofloxacin $(30 \mu \mathrm{g} / \mathrm{disc})$ and blank discs (impregnated with solvents followed by evaporation) were used as negative control as well as positive, respectively. The plates were incubated at $37^{\circ} \mathrm{C}$ for 24 hours for microbial growth. The antimicrobial activity of the extract was determined by measuring the diameter of zone of inhibition $(\mathrm{mm})$ at the end of the incubation period.

\subsection{Statistical Analysis}

The results were expressed as the mean \pm standard deviation (SD). Statistical significance of the mean mortality at each concentration was analyzed using one-way analysis of variance (ANOVA) and compared using Duncan's multiple range tests. Values of $\mathrm{p} \leq 0.05$ were taken to be statistically significant.

\section{Results and Discussion}

The different methanol extracts of leaves of B. acuminata at concentration $2.0 \mathrm{mg} / \mathrm{mL}$ significantly protected the lysis of human erythrocyte membrane induced by hypotonic solution whereas acetyl salicylic acid $(0.10 \mathrm{mg} / \mathrm{mL})$ used as standard (Table-1).

It is clear evident that the extractives of leaves of $B$. acuminata were highly effective in the membrane stabilizing activity as the extractives prevented the lysis of erythrocyte induced by hypotonic solution and heat.

In hypotonic solution induced condition the highest membrane stabilizing activity was exhibited by the Pet ether soluble fraction (PESF-418.26\%) followed by carbon tetra chlororide soluble fraction (CTCSF-418.26\%). Significant amount of membrane stabilizing activity were also present in methanol soluble fraction (MESF-13.46\%) and aqueous soluble fraction (AQSF-167.30\%).

On the other hand, heat induced condition the maximum membrane stabilizing activity was exhibited by the carbon tetra chlororide soluble fraction (CTCSF-853.3\%) followed by Methanol soluble fraction (MESF-423.88\%). Significant amount of membrane stabilizing activity were also present in Pet ether soluble fraction (PESF-81.77\%) and aqueous soluble fraction (AQSF-40.46\%).

The effect of synthetic and herbal anti-inflammatory agents on the stabilization of erythrocyte membrane exposed to hypotonic solution has been studied extensively. The 
erythrocyte membrane resembles to lysosomal membrane, the effect of drugs on the stabilization of erythrocyte could be extrapolated to the stabilization of lysosomal membrane [9].

The results showed that the extracts were potent on human erythrocyte adequately protecting it against hypotonic induced lysis. The activity was compared with standard anti-inflammatory drug (Acetyl Salicylic Acid). It has been reported that flavonoids exert profound stabilizing effects on lysosomes both in vitro and in vivo experimental animals while tannin and saponins have the ability to bind cations and other biomolecules, and are able to stabilize erythrocyte membrane.

The present investigation suggests that the membrane stabilizing activity of leaves of Bauhinia acuminata plays a significant role in its anti-inflammatory activity may be due to its high flavonoids and tannin content.

Prevention of leakage of serum proteins and fluids into the tissues during a period of increased permeability caused by inflammatory mediators by membrane stabilizes results [4]. Phytochemicals screening demonstrates that the plant extract contains flavonoids which have been reported to possess potent anti-inflammatory property $[5,6]$. The anti-inflammatory activity is may be inhibitory effect on enzymes involved in the production of the chemical mediators of inflammation and metabolism of arachidonic acid [7].
The Methanol extract of leaves of B.acuminata (MESF) and different partitionates i.e. Pet Ether(PESF), chloroform (CSF), carbon tetrachloride (CTCSF) and aqueous (AQSF) soluble partitionate of the methanol extract of leaves of $B$. acuminata were subjected to antimicrobial screening with a concentration of $400 \mu \mathrm{g} / \mathrm{disc}$ in every case. The results are given in the Table -2 .

In this study, the antimicrobial activity, among all extractives of leaves of Bauhinia acuminate was found to be negligible.

The Plant produces several secondary metabolites which are includes like phenolics, flavonoids,flavones, flavonols, coumarins, tannins, lectins, polypeptides, alkaloids and other compounds which support the plant defense against the microorganisms[8].

\section{Conclusion}

In the present study, demonstrate significant anti-inflammatory activity. The plant may be an economical, safe and easily available source of natural agents used in inflammation and anti-microbial. Future study would be conducted for identification of lead compounds and purification of the active principles of the plant responsible for the observed biological effects.

Table 1. Effect of different extractives of leaves of Bauhinia acuminata on hypotonic solution-induced haemolysis of erythrocyte membrane.

\begin{tabular}{llll}
\hline Sample code & Concentration & Absorbance & \% inhibition of haemolysis \\
\hline Hypotonic medium & $50 \mathrm{mM}$ & 3.225 & 0.118 \\
MESF & $2 \mathrm{mg} / \mathrm{mL}$ & 0.539 & 13.46 \\
PESF & $2 \mathrm{mg} / \mathrm{mL}$ & 0.289 & 418.26 \\
CTCSF & $2 \mathrm{mg} / \mathrm{mL}$ & 0.278 & 177.88 \\
AQSF & $2 \mathrm{mg} / \mathrm{mL}$ & 0.906 & 167.30 \\
Acetyl salicylic acid & $0.10 \mathrm{mg} / \mathrm{mL}$ & 71.9 \\
\hline
\end{tabular}

Table 2. Antimicrobial activity of test samples of Bauhinia acuminata

\begin{tabular}{|c|c|c|c|c|c|c|}
\hline \multirow{2}{*}{ Test m.o } & \multicolumn{6}{|c|}{ Diameter of zone of inhibition (mm) } \\
\hline & MESF & PESF & CTCSF & CSF & AQSF & Ciprofloxacillin \\
\hline \multicolumn{7}{|l|}{ Gram positive bacteria } \\
\hline Bacillus cereus & - & - & - & - & - & 15 \\
\hline Bacillus megaterium & - & - & - & - & - & 15 \\
\hline Bacillus subtilis & - & - & - & - & - & 17 \\
\hline Staphylococcus aureus & - & - & - & - & - & 21 \\
\hline Sarcina lutea & - & - & - & - & - & 17 \\
\hline \multicolumn{7}{|l|}{ Gram negative bacteria } \\
\hline Escherichia coli & - & - & - & - & - & 22 \\
\hline Pseudomonas aeruginosa & - & 2 & 3 & 4 & - & 17 \\
\hline Salmonella paratyphi & - & 3 & 2 & - & 3 & 15 \\
\hline Salmonella typhi & - & 3 & 1 & 6 & - & 20 \\
\hline Shigella boydii & - & - & - & - & - & 17 \\
\hline Shigella dysenteriae & - & - & - & 3 & - & 21 \\
\hline Vibrio mimicus & - & - & - & - & - & 16 \\
\hline Vibrio parahemolyticus & - & - & - & - & 5 & 15 \\
\hline \multicolumn{7}{|l|}{ Fungi } \\
\hline Candida albicans & - & - & - & - & - & 20 \\
\hline Aspergillus niger & - & - & - & - & - & 17 \\
\hline Sacharomyces cerevacae & - & - & - & - & 1 & 19 \\
\hline
\end{tabular}




\section{Abbreviations}

$\mathrm{ME}=$ Methanolic extract; $\mathrm{PESF}=$ Pet-ether soluble fraction; $\mathrm{CTCSF}=$ Carbon tetrachloride soluble fraction; CSF =Chloroform soluble fraction; $\mathrm{AQSF}=$ Aqueous soluble fraction of the methanolic extract of Bauhinia acuminate

\section{Acknowledgements}

We are acknowledging to Progati Medical Institute for their facilities to complete this work successfully.

\section{References}

[1] Verdcourt, B. 1979. A Manual of New Guinea Legumes. Office of Forests division of botany, Lae (Papua New Guinea). 645pp.

[2] Howard, Richard A. 1988. Flora of the Lesser Antilles: Leeward and Windward Islands. Vol. 4, Dicotyledoneae-Part 1. Arnold Arboretum, Harvard University. 673 pp.

[3] Sadipa nag, Anirban Paul, Ritu Parna Datta. Phytochemical analysis of methanolic extract of some medicinal plants. International Journals of scientific and research publications 2013; 3(4) p1648.

[4] Van Wagenen, B.C., Larsen, R., Cardellina, J.H., Ran dazzo, D., Lidert, Z.C. and Swithenbank, C. 1993. Ulosantoin, a potent insecticide from the sponge Ulosa ruetzleri. J. Org. Chem. 58, 335-337.

[5] Mounnissamy VM, Kavimani S, Balu V, Drlin QS: Evaluation of anti-inflammatory and membrane stabilizing properties of ethanol extract of Canjera rehedi. Iranian Journal of Pharmacology and Therapeutics 2008, 6:235-237.
[6] Shinde UA, Phadke AS, Nair AM, Mungantiwar AA, Dikshit VJ and Saraf MN: Preliminary studies on the immunomodulatory activity of Cedrus deodara wood oil. Fitoterapia 1999; 70: 333-339.

[7] Sikder MA, Rahman MA, Kaisar MA, Rahman MS, Hasan CM and Rashid MA: In vitro Antioxidant, reducing power, free radical scavenging and membrane stabilizing activities of seeds of Syzygium cumini L. Latin American Journal of Pharmacy 2011; 30: 781-5.

[8] Reyad-ul-Ferdous M, Azam MG and Hossain MD: Phytochemical screening, in-vitro membrane stabilizing and thrombolytic activities of Lophopetalum javanicum. Int J Pharm Sci Res 2014; 5(2): 350-53.

[9] Bauer AW, Kirbey WMM, Sherries JC, Truck M. Antibiotic susceptibility testing by standardized single disc method. Am J Clinical Pathol 1996; 45: 493- 496.

[10] Chaitanya R, Sandhya S, David B, Vinod KR, Murali S: HRBC Membrane Stabilizing Property of Roor, Stem and Leaf of Glochidion velutinum. International Journal of Research in Pharmaceutical and Biomedical sciences 2011; 2(1):256-259.

[11] Middleton E, Kandaswami C: Effect of flavonoids on immune and inflammatory cell function. Biochemical Pharmacology 1992; 43:1167-1179.

[12] Read MA: Flavonoids: naturally occurring anti-inflammatory agents. American Journal of Pathology 1995; 147:235-237.

[13] Oweyele B, Oloriegbe YY, Balaogun EA, Soladoye AO: Analgesis and anti-inflammatory properties of Nelsonia Canescens leaf extract. Journal of Ethnopharmacology 2005; 99:153-156.

[14] Md. Reyad-ul-Ferdous, Mosharaf Hossen and Fazle Noor Biswas. In-vitro potential antimicrobial and antioxidant activities of Lablab niger leaves. International Journal of Pharma Sciences and Research 2014; 5(6): 257-261. 